Interdisciplinary Research in Education

Volume 4, Issue 2, 2019: 208-214

DOI: https://doi.org/10.3126/ire.v4i2.27940

\title{
माध्यमिक तहमा सामाजिक अध्ययन शिक्षणको अवस्था
}

\author{
तेजप्रसाद सिगदेल \\ शिक्षा शास्त्र केन्द्रीय विभाग \\ त्रि.वि कीर्तिपुर ।
}

\begin{abstract}
सारसंक्षेप
मनिसलाई समय सापेक्ष तथा समाज सापेक्ष बनाजने शिक्षा नै सामाजिक शिक्षा अर्थात् सामाजिक अध्ययन हो। सामाजिक अध्ययनको आधार स्तम्भको रूपमा मानवीय सम्बन्ध, समकालिन समाज तथा सामाजिक विज्ञानलाई लिने गरिन्छ। नेपालको सर्द्धभमा माध्यमिक शिक्षा पाठ्यक्रम २०१४ लागु भएपछि इतिहास, भूगोल, राजनीतिकशास्त, नागरिकशास्त्र तथा अर्थशास्त्र आदि विषयका विषयवस्तुलाई समावेश गरी एकीकृत विषयको रूपमा सामाजिक अध्ययन विषयको पाठ्यक्रम निमार्ण गरी अनिवार्य विषयको रूपमा पठनपाठन हुदै आएको छ। यसरी एकीक्त पाठ्यक्रम अनुसार तयार पारिएको माध्यमिक तहको सामाजिक अध्ययन विषयको शिक्षण कार्य चुनौतिपूर्ण छ। सै सर्द्धभमा माध्यमिक तहको सामाजिक अध्ययन विषय शिक्षणको लागि आवश्यक जनशक्ति उपलब्धताको अवस्था, शिक्षण सामग्रीको उपलव्धताको अवस्था तथा शैक्षिक उपलब्धिको अवस्था, आदि पत्ता लगाउने उद्देश्यले चार ओटा सामुदायिक माध्यमिक विद्यालयहरूमा अध्ययन गरिएको थियो। यस लेखमा तिनै विद्यालयहरूमा सामाजिक अध्ययन विषय शिक्षण गर्नको लागि विशिष्टिकरण हासिल गरेका विषयगत शिक्षकहरू उपलब्ध नभाएको, आवश्यक शैक्षिक सामग्रीहरू विद्यालयमा पर्याप्त मात्रा उपलब्ध नभाका र उपलब्ध भाएका कतिपय शिक्षण सामग्रीहरूको प्रयोगमा ल्याउन नसकिने अवस्थामा रहेका तथा एसइइ परीक्षामा अन्य अनिवार्य विषयको तुलनामा सामाजिक अध्ययन विषयको औसत प्राप्ताइ कम आउने गरेको तथ्यलाई उजागर गरिएको छ।
\end{abstract}

मुख्य शब्दावली : समाज, संस्कृति, सामाजिक अध्ययन, एकीकृत विषय, समकालिन मुद्धाहरू, सामाजिक घटनाहरू, सामाजिक प्राणी।

\section{१. पृष्ठभूमि}

मानिस सामाजिक प्राणी हो । उसका क्रियाकलापहरू सामाजिक, सांस्कृतिक आर्थिक, राजनीतिक, तथा प्राकृतिक वातावरणबाट प्रभावित भइरहेको हुन्छ। समाजमा हुने सबै प्रकारका वस्तु तथा घटनाहरू समयको अन्तराल सँगसँगै परिवर्तन आउने गर्दछन्। यसरी समयको परिवर्तनसँगै समयानुकूल हुनसके मात्र अस्तित्वमा कायम रहन सक्दछ। मानिसलाई समयको अन्तराल सँगसँगै उसको समाज, वातावरण, परिस्थिति र आवश्यकता अनुसार समायोजित हुनका लागि निश्चित ज्ञान, सीप, कुशलता तथा शिक्षाको आवश्यकता पर्दछ। यो शिक्षा सामाजिक शिक्षाले प्रदान गर्दछ। तसर्थ समाजिक अध्ययन मानव र उसको 
माध्यमिक तहमा सामाजिक अध्ययन शिक्षणको अवस्था/209

सामाजिक तथा भौतिक वातावरणसँगको अन्तरक्रिया तथा मानवीय सम्बन्धका बारेमा अध्ययन गरिने विषय हो। सामाजिक अध्ययन शिक्षणको उद्देश्य बालबालिकाहरूलाई विद्यालय तह देखि नै घर परिवार, समुदाय, गाउँ, टोल, जिल्ला हुँदै राष्ट्र र अन्तर्राष्ट्रिय जगत सम्मको जानकारी दिलाउने हो। सोही कारण नेपालमा सामाजिक अध्ययनको एकिकृत पाठ्यक्रम निमार्ण गरी शिक्षण गराइदै आएको छ।

सामाजिक अध्ययनको प्रकृति र यसको शिक्षण सिकाईका सर्द्दभमा पाँडे (२०४३) ले उल्लेख गरे अनुसार, सामाजिक अध्ययनले बालबालिकाहरूमा सामाजिकीकरणको विकास गर्ने, आफ्नो दैनिक जीवनका समस्या समाधान गर्ने सीप, तार्किक कुशलता, नेतृत्वसीप, सामाजिक मूल्य र मान्यताको जानकारी, आर्थिक तथा सामाजिक कल्याणकारी कार्य, समसामयिक विषयको जानकारी, नागरिक सम्बन्धी शिक्षा, राष्ट्रिय तथा अन्तर्राष्ट्रिय भावनाको विकास गर्ने जस्ता कार्यहरू गर्दछ। यसको प्रकृति गतिशिल भएको र क्षेत्र वृहत भएकाले यसको शिक्षण कार्य उत्तिकै चुनौती पूर्ण छ। सोही कारण सामाजिक अध्ययनको शिक्षणमा समाज बुक्केको, समुदाय बुक्केको विषयगत शिक्षक आवश्यकता पर्दछ।

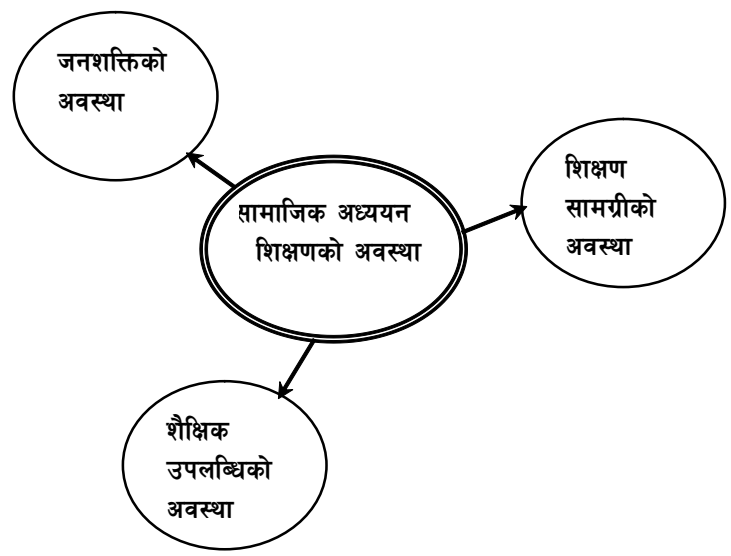

त्यसैगरी सामाजिक अध्ययन विषयको पाठ्यक्रमले तोकेको उद्देश्य पुरा हुनेगरी राखिएका विषयवस्तुहरूको शिक्षण गर्दा उपयुक्त शिक्षण विधि र शिक्षण सामग्रीको प्रयोग गर्नु अति आवश्यक हुन्छ भन्दै कैयूम (२०७२) ले उल्लेख गरे अनुसार कयौ पटक सुनेका कुरा भन्दा एकै पटक हेरेका कुरा दिगो एवं लामो समय सम्म स्मरणमा रहने गर्दछ। यसरी सामाजिक अध्ययनको शिक्षणमा विषयगत शिक्षक र शिक्षण सामग्रीको उपलब्धता र प्रयोग अति आवश्यक मानिन्छ। तर विभिन्न समयमा गरिएका अध्ययनहरूमा सामुदायिक विद्यालयहरू सामाजिक अध्ययन विषय शिक्षण गर्दा आवश्यक पर्ने शिक्षण सामग्रीको अभाव रहेको, सामाजिक अध्ययन विषयको प्रकृति अनुसार शिक्षकहरूलाई तालिमको व्यवस्था हुन नसक्दा सामाजिक अध्ययन विषयको शिक्षण सिकाइ प्रक्रिया प्रभावकारी हुन नसकेको निश्र्कष निकालेको पाइन्छ। जसमध्ये खनाल (२०६७) ले माध्यमिक तहमा सामाजिक अध्ययन शिक्षण शीर्षकमा गरिएको शोध अध्ययनमा सामाजिक अध्ययन विषयको शिक्षण गर्दा शिक्षकले उपयुक्त शिक्षण विधिको प्रयोग नगरेको, विद्यालयमा सामाजिक अध्ययन विषय शिक्षण गर्दा आवश्यक पर्ने शैक्षिक सामग्रीहरूको अभाव रहेको तथा सामाजिक अध्ययन विषय शिक्षण गर्ने अधिकांस शिक्षकहरू तालिम अप्राप्त रहेको निर्करष निकालेको पाइन्छ। त्यसैगरी पनेरु (२०६४) ले माध्यमिक तहको सामाजिक अध्ययन शिक्षणमा शिक्षण सामग्रीको 
उपलब्धता र प्रयोगको अवस्था शीर्षकमा गरेको शोध अध्ययनमा पनि सामुदायिक माध्यमिक विद्यालयमा सामाजिक अध्ययन गर्ने विषयगत र तालिम प्राप्त शिक्षकहरू उपलब्ध नभएका, शिक्षक निर्देशिकामा उल्लेख भए अनुसारका सामाजिक अध्ययन शिक्षणको लागि आवश्यक पर्ने शिक्षण सामग्रीहरू विद्यालयमा प्रर्याप्त उपलब्ध नभएको, उपलब्ध सामग्रीहरूको कक्षाकोठामा अत्यान्त न्यून मात्रामा प्रयोग हुने गरेको, शिक्षकहरूले स्थानिय सामग्रीको निमार्ण र प्रयोगमा खासै ध्यान नदिएको तथा विद्यालयमा आर्थिक स्रोतको अभावका कारण आवश्यक शिक्षण सामग्रीहरू खरिद गर्न नसकेको निर्ष्कष निकालेको पाइन्छ।

यसरी विभिन्न अध्ययनहरू सामाजिक अध्ययन शिक्षणका लागि आवश्यक पर्ने शिक्षकको अवस्था, शिक्षण सामग्रीको उपलब्धता र प्रयोगको अवस्थामा केन्द्रीत छन् विषयगत शैक्षिक उपलब्धिहरू खोजि गरिएको पाइँदैन। तर यस लेखमा जनशक्तिको अवस्था, शिक्षण सामग्रीको अवस्था को अलवा एसइइमा विद्यार्थीहरूले सामाजिक अध्ययन र अन्य अनिवार्य विषयहरूमा प्राप्त गरेको शैक्षिक उपलब्धिको अवस्थाको पनि तुलना गर्ने प्रयास गरिएको छ।

\section{२. विधि}

यो लेख गुणात्मक ढाँचामा व्याख्यात्मक एवं विश्लेश्षणात्मक शैलीमा तयार पारिएको छ। तनहूँ जिल्लाको शुक्लागण्डकी नगरपालिकामा रहेको जनप्रेमी मा.वि लामागाँऊ स्रोत केन्द्र अन्तर्गत पर्ने ७ वटा सामुदायिक माध्यमिक विद्यालयहरूमध्ये संम्भावनायुक्त नमुना छनोट विधिका आधारमा $\checkmark$ वटा माध्यमिक विद्यालय र ती विद्यालयका प्रधानाध्यापक तथा सामाजिक शिक्षकहरूलाई नमुनाको रूपमा छनोट गरि गरिएको अध्ययनका आधारमा यो लेख तयार पारिएको छ। प्राथमिक तथ्याङ्कमा आधारित रहको यस लेखमा आवश्यकता अनुसार द्वितीयक तथ्याङ्कको पनि प्रयोग गरिएको छ। नमुना छनोट गरिएका विद्यालयका प्रधानाध्यापक तथा शिक्षकहरूसँग अन्तर्वार्ता प्रश्नावलीको सहायताले तथ्याङ्क सङ्कलन गरिएको छ भने रुजुसुचि, अवलोकन तथा अभिलेख अध्ययनबाट पनि आवश्यकता अनुसार तथ्याङ्क लिइएको छ। त्यसैगरी विभिन्न अध्ययन प्रतिवेदन, लेख तथा पुस्तकहरूबाट आवश्यकता अनुसार द्वितीयक तथ्याङ्क प्रयोग गरिएकोछ। यसरी विभिन्न स्रोतबाट सङ्कलित तथ्याङ्कहरूको नतिजालाई वर्णनात्मक रूपमा विश्लेषण गरिएको छ। नतिजा विश्लेषण गर्ने कममा गाउँफर्को मा.वि लाई १, तालबेसी मा.वि लाई २, आधारभुत मा.वि लाई ३ र जनप्रेमी मा.वि लाई $\checkmark$ गरी विद्यालयको सांकेतिकरण गरिएको छ।

\section{३. नतिजा विश्लेषण}

पाठ्यक्रम प्रभावकारी रूपमा कार्यान्वयन गर्ने कुरा शिक्षण सिकाइ क्रियाकलापमा भर परेको हुन्छ । शिक्षण सिकाइ क्रियाकलापको व्यवस्थापन गर्नु एक जटिल कार्य हो। शिक्षणका क्रममा केही कुराहरूको व्यवस्थापनमा गर्न सकिएमा शिक्षण सिकाइ क्रियाकलाप प्रभावाकरी बन्न जान्छ। नमुना छनोट गरिएका सामुदायिक माध्यमिक विद्यालयहरूमा सामाजिक अध्ययन शिक्षणको अवस्थालाई यहाँ प्रस्तुत गरिएको छ। 
माध्यमिक तहमा सामाजिक अध्ययन शिक्षणको अवस्था/211

\section{३.१ विषयगत जनशक्तिको अवस्था}

शिक्षकलाई सिकारुको दोस्रो गुरुको रूपमा लिने गरिन्छ। विभिन्न परिवेशबाट आएका बालबालिकाहरूलाई शिक्षा/ज्ञान दिएर पूर्ण बनाउने काम शिक्षकले गरेको हुन्छ। शिक्षक जतिबढी विषयवस्तुमा दक्ष अनुभवी एवं तालिम प्राप्त हुन्छ त्यति नै सिकारुलाई बढ़ी भन्दा बढ़ी ज्ञान दिन सक्दछ। विद्यालयमा विषयवस्तुमा राम्रो ज्ञान भएको आधुनिक शिक्षण विधि एवं सामग्रीको प्रयोग गर्न जान्ने दक्ष शिक्षक उपलब्ध भएमा शिक्षण सिकाइ क्रियाकलाप प्रभावकारी बन्ने एवं शैक्षिक उपलब्धि बढ़ी हुने विश्वास गरिन्छ। सामुदायिक विद्यालयमा सामाजिक अध्ययन विषय शिक्षण गर्ने जनशक्तिको अवस्था सम्बन्धी विवरण तालिका ३.१ मा प्रस्तुत गरिएको छ :-

तालिका ३. १ : बिद्यालयमा उपलब्ध जनशक्तिको अवस्था

\begin{tabular}{|l|c|}
\hline \multicolumn{1}{|c|}{ शिक्षकको विवरण } & सड्ख्या \\
\hline न्यूनतम योग्यता मात्र भएका शिक्षक & २ \\
\hline माथिल्लो योग्यता भएका शिक्षक & २ \\
\hline सामाजिक विज्ञान समुहबाट विशिष्टिकरण गरेका शिक्षक & ३ \\
\hline अन्य विषयबाट विशिष्टिकरण गरेका शिक्षक & २ \\
\hline तालिम प्राप्त शिक्षक & २ \\
\hline तालिम अप्राप्त शिक्षक & \\
\hline
\end{tabular}

स्रोत : स्थलगत अध्ययन, २०७४।

तालिका अनुसार सामुदायिक माध्यमिक विद्यालयमा सामाजिक अध्ययन विषय शिक्षण गर्ने शिक्षकहरूको योग्यता माध्यमिक तहको शिक्षक हुनको लागि आवश्यक पर्ने न्यूनतम योग्यता सबै शिक्षकहरूमा रहेको पाइन्छ भने २ जना शिक्षकको माथिल्लो योग्यता समेत रहेको पाइन्छ। त्यसैगरी १ जना शिक्षकले मात्र सामाजिक विज्ञान समुहबाट विशिष्टीकरण हासिल गरेको पाइन्छ भने ३ जना शिक्षकहरूको विशिष्टीकरण विषय सामाजिक समुह भन्दा बाहिरको रहेको पाइन्छ। त्यसैगरी २ जना सामाजिक शिक्षक तालिम प्राप्त भएको पाइन्छ भने २ जना सामाजिक शिक्षक तालिम अप्राप्त रहेको पाइन्छ। अध्ययनमा सहभागि ३ वटा विद्यालयका प्रधानाध्यापकहरूले पनि विद्यालयमा विषयगत र तालिमप्राप्त शिक्षकहरू उपलब्ध हुन नसकेको बताएका थिए। यसरी सामुदायिक माध्यमिक विद्यालयहरूमा सामाजिक अध्ययन विषय शिक्षण गर्नको लागि सामाजिक विज्ञान समुहबाट विशिष्टिकरण हासिल गरेका तथा तालिम प्राप्त बिषयगत शिक्षकहरू उपलब्ध हुनसकेको पाइँदैन ।

\section{३.२ शिक्षण सामग्री उपलब्धताको अवस्था}

पाठ्यक्रमको कार्यान्वयन गर्ने थलो विद्यालय हो । त्यसको सफलता वा असफलता शिक्षण सिकाइ क्रियाकलापमा पनि भर परेको हुन्छ। अर्थात् पाठ्यक्रम जतिसुकै राम्रो भएतापनि त्यसको सफल कार्यान्वयन भएन भने पाठ्यक्रम नै असफल ठहरिन्छ। तसर्थ उपयुक्त विधि एवं सामग्रीको प्रयोग गर्नु अति आवश्यक हुन्छ। उपयुक्त विधि एवं सामग्रीको सहायताले गरिएको शिक्षण सिकाइ क्रियाकलाप प्रभावकारी, दिगो एवं उपलब्धिपूर्ण हुन्छ। सामाजिक विषयमा समेटिएका भूगोल, राजनीतिशास्त्र, इतिहास, समाजशास्त्र, नागरिकशास्त्र, मानवशास्त्र जस्ता विषयका विषयवस्तुहरूलाई सहि ढड्गले शिक्षण गर्न र 
ति विषयहरूको वास्तविक ज्ञान, सीप र धारणा विद्यार्थीहरूलाई उपलब्ध गराउन शैक्षिक सामग्रीको प्रयोग अपरिहार्य मानिन्छ। विषयवस्तु अनुरूप उपयुक्त शिक्षण सामग्रीको प्रयोग गरी शिक्षण गर्दा विद्यार्थीमा पढाइप्रति ध्यान केन्द्रित हुने, बुकाइ दिगो हुने र नतिजा राम्रो आउने विश्वास गरिन्छ। सामाजिक अध्ययन भित्र करिब २० प्रतिशत विषयवस्तु भूगोल सँग सम्बन्धित रहेकाले सामाजिक अध्ययनको शिक्षणमा शिक्षण सामग्री भनै महत्त्वपर्ण मानिन्छ। माध्यमिक तहको सामाजिक अध्ययन शिक्षण गर्दा आवश्यक पर्ने विभिन्न प्रकारका शिक्षण सामग्रीको विवरण सामाजिक अध्ययन शिक्षक निर्देशिकामा उल्लेख गरिएको पाइन्छ। सोही निर्देशिकामा उल्लेखित शिक्षण सामग्रीहरूको विवरणको आधारमा तयार पारिएको रुजुसूची अनुसार सड्कलन गरिएको शैक्षिक सामग्रीको उपलब्धता सम्बन्धि विवरणलाई तालिका ३.२ मा प्रस्तुत गरिएको छ :-

तालिका ३.२. : विद्यालयमा शिक्षण सामग्री उपलब्धताको अवस्था

\begin{tabular}{|c|c|c|}
\hline शिक्षण सामग्रीको नाम & $\begin{array}{l}\text { उपलब्ध भएका } \\
\text { विद्यालय सङ्ख्या }\end{array}$ & $\begin{array}{l}\text { उपलब्ध नभएका } \\
\text { विद्यालय सड्ख्या }\end{array}$ \\
\hline $\begin{array}{l}\text { नक्सा (नेपालको नक्सा, महादेशको नक्सा, विश्वको } \\
\text { नक्सा, विश्वको नक्सा, वनस्पति नक्सा) }\end{array}$ & $\curlyvee$ & - \\
\hline ज्वालामुखी तथा भूकम्प सम्बन्धी नक्सा & 9 & ३ \\
\hline ग्लोब & $\gamma$ & - \\
\hline पत्रपत्रिका, पोष्टर, चित्र & $\gamma$ & - \\
\hline नमुना & - & $\gamma$ \\
\hline चार्ट & 9 & ३ \\
\hline सुचिकृत तालिका & - & $\gamma$ \\
\hline $\begin{array}{l}\text { तस्वीर (विश्वयुद्धका घटनाका तस्वीरहरू, आर्थिक } \\
\text { उत्पादन देखाइएका तस्वीरहरू, विकास आयोजनाका } \\
\text { तालिकाहरू, कोतपर्व, भण्डारखाल पर्व, अलौ पर्व भएका } \\
\text { स्थलहरूका तस्वीरहरू । }\end{array}$ & - & $\gamma$ \\
\hline
\end{tabular}

स्रोत : स्थलगत अध्ययन, २०७४।

तालिकामा प्रस्तुत तथ्याङ्क अनुसार नक्सा, ग्लोब तथा पत्रपत्रिका, पोष्टर र चित्र सबै विद्यालयमा उपलब्ध भए तापनि नमुना, सुचिकृत तालिका तथा तस्वीरहरू कुनै पनि विद्यालयमा उपलब्ध भएको पाइइैन । त्यसैगरी ज्वालामुखी तथा भूकम्प सम्बन्धी नक्सा एवं चार्ट 9 वटा विद्यालयमा उपलब्ध भएतापनि ३ वटा विद्यालयमा उपलब्ध भएको पाइंदैन। केही विद्यालयमा उपलब्ध शिक्षण सामग्रीहरूको भौतिक अवस्था अत्यन्त नाजुक रहेको र कक्षा कोठामा प्रयोगमा ल्याउन नसकिने अवस्थामा रहेको पनि पाइन्छ। पाठ्यक्रम विकास केन्द्रले प्रकाशन गरेको सामाजिक अध्ययन विषयको शिक्षक निर्देशिकामा एकाई अनुसार आवश्यक पर्ने शिक्षण सामग्रीको विवरण स्पष्ट रूपमा उल्लेख गरिएको छ। तर सामुदायिक विद्यालयहरूमा निर्देशिका उल्लेख भए अनुसारका पू० प्रतिशत सामग्री पनि उपलब्ध भएको पाइँदैन। विभिन्न एकाईमा अति आवश्यक पर्ने तस्वीर, पोष्टरहरू, चित्रहरू, ऐतिहासिक लेख रचना, ऐतिहासिक पत्रपत्रिकाको कटिङ, विभिन्न विश्वयुद्धका घटनाका तस्वीरहरू, आर्थिक उत्पादन देखाइएका तस्वीरहरू, विकास आयोजनाका 
माध्यमिक तहमा सामाजिक अध्ययन शिक्षणको अवस्था/213

तालिकाहरू, कोतपर्व, भण्डारखाल पर्व, अलौ पर्व भएका स्थलहरूका तस्वीरहरू, भूकम्प नाप्ने यन्त्र, जस्ता सामग्रीहरू विद्यालयमा उपलब्ध भएको पाइँदैन भने स्थानीय सामाग्रीको निमार्ण र प्रयोग पनि न्युन मात्र हुने गरेको पाइन्छ।

अध्ययनमा सहभागि विद्यालयका प्रधानाध्यापक तथा सामाजिक शिक्षकहरूले पनि विद्यालयमा सामाजिक अध्ययन विषयसँग सम्बन्धित पर्याप्त शिक्षण सामग्री उपलब्ध नभएको बताए । यसरी विद्यालयमा सामाजिक अध्ययन विषय शिक्षण गर्दा आवश्यक पर्ने शिक्षण सामग्रीहरू पर्याप्त मात्रामा उपलब्ध भएको पाइंदैन ।

\section{३.३ शैक्षिक उपलब्धीको अवस्था}

शिक्षण सिकाइ क्रियाकलापको प्रभावकारिता नतिजामा भर पर्ने पर्दछ, अथात् शिक्षण सिकाइ क्रियाकलापको सफलता या असफलता जाँच्ने कडी मध्ये एउटा महत्त्वपूर्ण कडी शैक्षिक उपलब्धी पनि हो। नमुना छनोट गरिएका विद्यालयका विद्यार्थीहरूको वि.स २०७२ दखि २०७४ साल सम्मको ३ बर्षको एसइइ परीक्षामा अनिवार्य विषयहरूमा प्राप्त गरेका औसत प्राप्ताङूलाई तालिका ३.३ मा प्रस्तुत गरिएको छ :-

तालिका ३.३ : अनिवार्य विषयमा विद्यार्थीहरूको औसत प्राप्ताङ

\begin{tabular}{|c|c|c|c|c|c|c|c|c|c|c|c|c|}
\hline \multicolumn{13}{|c|}{ विद्यार्थीको औसत प्राप्ताङ़ (प्रतिशतमा) } \\
\hline \multirow{3}{*}{ विषय } & \multicolumn{4}{|c|}{ वि.स २०७२ } & \multicolumn{4}{|c|}{ वि.स २०७३ } & \multicolumn{4}{|c|}{ वि.स २०७४ } \\
\hline & \multicolumn{4}{|c|}{ विद्यालय संकेत } & \multicolumn{4}{|c|}{ विद्यालय सङ्केत } & \multicolumn{4}{|c|}{ विद्यालय सङ्केत } \\
\hline & 9 & २ & ३ & $\gamma$ & 9 & २ & ३ & $\gamma$ & 9 & २ & ३ & $\gamma$ \\
\hline नेपाली & $y=.2 \gamma$ & पू. दर & yง. 49 & प३. 95 & पy. 89 & y૪.२७ & yง.9y & पy.६२ & y९. $2 \gamma$ & प६. २ू & $y=.29$ & प६.६१ \\
\hline गणित & yू. 59 & ४५.ॅ९ & प૪.६९ & पद६.९२ & पू६.Oद & $y<.59$ & yy.yr & प८.६९ & पू६.६६ & 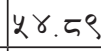 & y७ ६. & पू. 29 \\
\hline अड्ग्रेजी & पर.०९ & ૪У.ढ३ & प9. ७० & ४. ५q & प२ २. ४९ & ૪७.३५ & ૪९.३१ & ४๘. $९ ९$ & 49.09 & yo. ᄃ३ & ४२२३३७ & 29.95 \\
\hline विज्ञान & प६६.२૪ & 29.90 & प३३.३९ & प२. २३ & पू६.२૪ & y३. ७६ & yy. 80 & y३.१२ & $y=8 z$ & पर ૨. ७९ & yू. $8 \rho$ & y૪.२१ \\
\hline $\begin{array}{l}\text { सामाजिक } \\
\text { अध्ययन }\end{array}$ & YY.OZ & ૪৩. ३৭ & पर.६६ & ४९.७३ & पू. ५९ & yo.29 & ૫३.६१ & पू. ऽ७ & $y \gamma . \rho 2$ & y३.३९ & $y \gamma . y \xi$ & पू३. \\
\hline
\end{tabular}

स्रोत : विद्यालयको अभिलेख ।

तालिका अनुसार २०७२ देखि २०७४ साल सम्मको एसइइमा विद्यार्थीहरूले अनिवार्य विषयहरूमा प्राप्त गरेका औसत प्राप्ताङ्कलाई हेर्दा नेपाली, गणित तथा विज्ञान विषयको तुलनामा सामाजिक अध्ययन विषयमा औसत प्राप्ताङ कम र अंग्रेजी विषयमा भन्दा बढी आएको पाइन्छ। यसरी विद्यार्थीहरूले सामाजिक अध्ययन विषयमा तुलनात्मक रूपमा कम अङ्क ल्याउनुको मुख्य कारण सामाजिक अध्ययन विषयको विषयवस्तु पृथक खालको हुनु र विषयवस्तुले समेटेको क्षेत्र व्यापक भएका कारण तोकिएको समयावधीमा सबै विषयवस्तुको राम्रोसँग विद्यार्थीहरूलाई ज्ञान दिलाउन कठिन भएको भनाई सामाजिक शिक्षकहरूको रहेको पाइन्छ। त्यसैगरी विद्यालयमा विषयगत शिक्षक उपलब्ध नहुनु र सामाजिक अध्ययन शिक्षण गर्दा आवश्यक पर्ने सामग्रीहरू पर्याप्त उपलब्ध नहुदाँ त्यसको असर नतिजामा परेको भनाई अधिकांश प्रधानाध्यापकहरूको रहेको पाइन्छ। 


\section{४. निष्कर्ष}

सामुदायिक माध्यमिक विद्यालयमा सामजिक अध्ययन शिक्षणको अवस्था पत्ता लगाउने उद्देश्यले $\checkmark$ वटा सामुदायिक माध्यमिक विद्यालय र ती विद्यालयका प्रधानाध्यापक र सामाजिक शिक्षकहरूलाई नमुनाको रूपमा छनोट गरी तथा विद्यालयको अभिलेख अध्ययनको आधारमा तयार पारिएको यस लेखमा निम्न निर्श्कष निकालिएको छ। सामुदायिक माध्यमिक विद्यलयहरूमा सामाजिक अध्ययन विषय शिक्षण गर्नको लागि सामाजिक विज्ञान शिक्षामा विशिष्टिकरण हासिल गरेका विषयगत शिक्षकहरू उपलब्ध भएको पाइँदैन। त्यसैगरी सामाजिक अध्ययन विषय शिक्षण गर्दा आवश्यक पर्ने शैक्षिक सामग्रीहरू पनि विद्यालयमा पर्याप्त मात्रा उपलब्ध नभएका र उपलब्ध भएका कतिपय शिक्षण सामग्रीहरूको भौतिक अवस्था अत्यन्त नाजुक र प्रयोगमा ल्याउन नसकिने अवस्थामा रहेको पाइन्छ। सामाजिक शिक्षकले स्थानीय रूपमा निर्माण गरी प्रयोगमा ल्याउन सकिने स्थानिय शिक्षण सामग्रीको निर्माण र प्रयोगमा त्यति चासो दिएको पाइँदैन । त्यसैगरी अन्य अनिवार्य विषयको तुलनामा सामाजिक अध्ययन विषयको औसत प्राप्ताइ कम आउने गरेको पाइन्छ। त्यसरी विद्यार्थीको नतिजा र शैक्षिक उपलब्धि स्तरमा कम हुनुका विभिन्न कारणहरूमध्ये एउटा कारण विद्यालयमा बिषयगत सामाजिक शिक्षक उपलब्ध नहुनु पनि एउटा कारण रहेको भनाई सरोकारवालाहरू पनि रहेको हुदाँ विद्यालयहरूमा सामाजिक शिक्षक नियुक्त गर्दा सामाजिक विज्ञान समुहबाट विशिष्टिकरण हासिल गरेको हुनुपर्ने नीतिगत व्यवस्था भएमा सामाजिक अध्ययन विषयको शिक्षण प्रभावकारी र नतिजामा सुधार आउन सक्ने देखिन्छ।

\section{सन्दर्भसूची}

कैयूम, अब्दुल, (२०७२), सामाजिक अध्ययन शिक्षण, काठमाडौं : प्रशान्ति प्रकाशन, पुतलीसडक, काठमाडौं।

खनाल, पेशल (२०...), शैक्षिक अनुसन्धान पद्धति, काठमाण्डौं : सनलाइट पब्लिकेशन प्रा.लि. कीर्तिपुर । खनाल, लोकराज (२०६७), माध्यमिक तहमा सामाजिक अध्ययन शिक्षण : अप्रकाशित शोधपत्र, त्रि.वि. कीर्तिपुर ।

पनेरु, दानबहादुर (२०६६), माध्यमिक तहको सामाजिक अध्ययन शिक्षणमा शिक्षण सामग्रीको उपलब्धता र प्रयोगको अवस्था : अप्रकाशित शोधपत्र, त्रि. वि कीर्तिपुर ।

पाँडे, रामकुमार (२०४३), सामाजिक शिक्षा सिद्धान्त र शिक्षण, काठमाडौं : रत्नपुस्तक भण्डार, भोटाहिटी ।

नेपाल सरकार, (२०६५) शिक्षक निर्देशिका सामाजिक अध्ययन कक्षा ९ र १० : पाठ्यक्रम विकास केन्द्र, सानोठिमी भक्तपुर ।

शिक्षा विभाग (२०६४), सामाजिक अध्ययन शिक्षण पुरक सामग्री माध्यमिक तह : सानोठिमी भक्तपुर । 